\title{
Diâmetro de estacas e substratos na propagação vegetativa de maniçoba, Manihot glaziovii Muell. Arg. ${ }^{1}$
}

\author{
Diameter of cuttings and substrates in the vegetative propagation of maniçoba \\ Manihot glaziovii Muell. Arg.
}

\author{
Leonardo Elias Ferreira ${ }^{2 *}$, Leonaldo Alves de Andrade $^{3}$, Gerlandio Suassuna Gonçalves ${ }^{2}$, Eliziete Pereira de \\ Souza $^{4}$ e Heriverta Virgínio Ferreira ${ }^{5}$
}

\begin{abstract}
Resumo - Objetivou-se com este trabalho estudar a influência do diâmetro das estacas e dos substratos na propagação vegetativa de maniçoba, Manihot glaziovii Muell. Arg. Utilizou-se o delineamento em blocos casualizados em esquema fatorial $10 \times 3$, sendo 10 substratos e 3 diâmetros de estacas, totalizando 30 tratamentos, oriundos das combinações entre substratos e diâmetros de estacas, com 4 repetições e 8 estacas por parcela. Os diâmetros das estacas corresponderam a: 0,5 a 1,0 cm (D1); 1,1 a 2,0 cm (D2) e 2,1 a 3,0 cm (D3). Foram utilizados 10 substratos: terra (S1); areia (S2); terra+areia: 1:1 (S3); terra+areia: 2:1 (S4); terra+areia: 1:2 (S5); terra+esterco: 1:1 (S6); areia+esterco: 1:1 (S7); terra+esterco: 2:1 (S8); areia+esterco: 2:1 (S9) e terra+areia+esterco: 1:1:1 (S10). As estacas lenhosas foram retiradas de plantas matrizes em repouso vegetativo, com comprimento de $25 \mathrm{~cm}$ e base cortada em bisel. Avaliou-se: percentual de estacas enraizadas; número de raízes; número de brotações; diâmetro e comprimento das brotações; número de folhas; massa seca das brotações e massa seca das raízes, obtidos aos 70 dias após instalação do experimento. Os melhores resultados para todas as variáveis estudadas foram obtidos com estacas de diâmetros entre 1,1 a 2,0 cm e entre 2,1 a 3,0 cm, com substratos que incluíram areia + esterco na sua composição. Tais tratamentos proporcionaram percentagens de enraizamento da ordem de 70 a $80 \%$.
\end{abstract}

Palavras-chave - Maniçoba. Plantas. Propagação por estaquia.

\begin{abstract}
This study aims to evaluate substrates and cuttings diameter influence in the vegetative propagation of Manihot glaziovii Muell.Arg. A design in randomized blocks using a $10 \times 3$ factorial scheme was used, being 10 substrates and 3 cuttings diameter, totaling 30 treatments, from the combinations between substrates and cuttings diameter, with 4 replications and 8 cuttings per plot. Diameters corresponded: 0.5 to $1.0 \mathrm{~cm}$ (D1); 1.1 to $2.0 \mathrm{~cm}$ (D2) and 2.1 to $3.0 \mathrm{~cm}$ (D3). Substrates used were: soil (S1); sand (S2); soil + sand: 1:1 (S3); soil + sand: 2:1 (S4); soil + sand: 1:2 (S5); soil + manure: 1:1 (S6); sand + manure: 1:1 (S7); soil + manure: 2:1 (S8); sand + manure: 2:1 (S9) and soil + sand + manure: 1:1:1 (S10). Woody cuttings were collected from matrix plants in vegetative rest. It was evaluated: percentage of rooted cuttings; roots number; shoots number; shoots length and diameter; leaves number; shoots dry matter and roots dry matter, obtained 70 days after experiment installation. Treatments influenced the analyzed variables. The best results to all studied variables were obtained in cuttings with diameters D2 and D3 and substrates which included sand + manure in their composition. Such treatments provided rooting percentage in the order of 70 to $80 \%$.
\end{abstract}

Key words - Maniçoba. Plants. Propagation of Cutting.

\footnotetext{
* Autor para correspondência

${ }^{1}$ Recebido para publicação em 09/07/2009; aprovado em 04/06/2010

Pesquisa realizada no Departamento de Fitotecnia, CCA/Universidade Federal da Paraíba, com recurso da própria universidade

${ }^{2}$ Programa de Pós-Graduação em Agronomia, CCA/UFPB, Areia-PB, Brasil, 58.397-000, 1.elias@yahoo.com.br; gsuassunaagro@hotmail.com ${ }_{3}^{3}$ Departamento de Fitotecnia CCA/UFPB, Areia-PB, Brasil, 58.397-000, landrade@cca.ufpb.br

${ }^{4}$ Instituto Federal do Ceará, Campus Crato, Programa de Pós-graduação em Agronomia, CCA/UFPB, Areia-PB, Brasil, elizietep@yahoo.com.br

${ }^{5}$ Centro de Ciências Agrárias/UFPB, Areia-PB, Brasil, 58.397-000, heriverta@hotmail.com
} 


\section{Introdução}

A maniçoba, Manihot glaziovii Muell. Arg., espécie nativa do Brasil, pertence à família Euphorbiaceae e ocorre principalmente no semiárido do Nordeste brasileiro, embora haja registros de sua ocorrência, também nos Estados do Mato Grosso e do Pará. Segundo Beltrão et al. (2006), esta espécie é considerada um recurso forrageiro de boa qualidade e, por esta razão, pode ser cultivada de forma sistemática, visando aumentar a oferta de forragem durante o período crítico de escassez de alimentos.

A propagação da maniçoba é feita geralmente, por sementes, porém a mesma tem dormência e germinação irregular, o que dificulta o cultivo da espécie (FIGUEIREDO, 1989). A propagação clonal, através da estaquia é uma técnica vantajosa, que além de maximizar a produção de mudas em menor tempo, gera indivíduos geneticamente iguais à planta matriz e viabiliza uma seleção mais eficiente em relação à reprodução sexuada e (FERRARI et al., 2004; NEVES et al., 2006), sendo esta técnica de propagação vegetativa, a mais comumente utilizada para a clonagem de plantas lenhosas (GRATIERI-SOSSELLA et al., 2008).

De acordo com Hartmann et al. (1990), a propagação clonal é fundamental para a obtenção de material homogêneo, uma vez que permite fixar as características genéticas desejadas, porém, segundo Souza e Lima (2005), esta técnica depende de fatores intrínsecos e extrínsecos às plantas matrizes tais como: diâmetro das estacas, estado nutricional, fenofase, natureza dos substratos e época do ano.

Apesar da importância e vantagens da propagação assexuada, as informações técnicas disponíveis sobre a clonagem da maniçoba são escassas, o que limita a obtenção de mudas com características produtivas desejáveis, sendo o diâmetro das estacas e o substrato importantes fatores que podem influenciar a propagação vegetativa dessa espécie.

De acordo com Fachinello et al. (1995), o diâmetro das estacas afeta o potencial de enraizamento, onde o diâmetro ideal varia conforme a espécie e a natureza das estacas. Biondi et al. (2008) avaliaram o potencial de enraizamento de estacas caulinares lenhosas de Tecoma stans com diferentes diâmetros $(\mathrm{T} 1=0,60-0,80 \mathrm{~cm}$; $\mathrm{T} 2=0,81-1,00 \mathrm{~cm}$ e T3 $=1,01-1,20 \mathrm{~cm})$ e verificaram $100 \%$ de enraizamento em todos os tratamentos.

Os substratos influenciam tanto na emissão de raízes adventícias quanto no desenvolvimento destas. Para promover o desenvolvimento radicular é necessário que o substrato tenha boa capacidade de retenção de água e aeração (JABUR; MARTINS, 2002), homogeneidade, boa porosidade, boa capacidade de troca catiônica, e serem isentos de pragas e organismos patogênicos (SANTOS et al., 2000), devendo ser de baixo custo e fácil acesso.

Contudo, apesar da influência dos substratos na rizogênese, praticamente inexistem pesquisas sobre o seu uso na propagação assexuada da maniçoba, o que tem dificultado a produção de mudas da mesma. Diante do exposto, objetivou-se no presente estudo avaliar a influência de diferentes diâmetros de estacas e composições de substratos no enraizamento de maniçoba, buscando-se, com isto, desenvolver uma metodologia para propagação vegetativa desta espécie.

\section{Material e métodos}

O experimento foi realizado no viveiro florestal do Departamento de Fitotecnia e Ciências Ambientais, Centro de Ciências Agrárias da UFPB, Campus II, em Areia - PB. O clima da região é classificado como As (Tropical quente e úmido), de acordo com a classificação de Köppen. A precipitação pluviométrica média é de $1.500 \mathrm{~mm} \mathrm{ano}^{-1}$, a umidade relativa do ar mantém-se em torno de $80 \%$ e a temperatura média anual oscila de 22 a $26{ }^{\circ} \mathrm{C}$ (BRASIL, 1972).

$\mathrm{O}$ delineamento experimental utilizado foi em blocos casualizados, em arranjo fatorial $10 \times 3$ (substratos $\mathrm{x}$ diâmetros da estaca), com 4 repetições e 8 estacas por parcela, totalizando 30 tratamentos e 960 estacas. Os substratos utilizados foram: terra (S1); areia (S2); terra + areia: 1:1 (S3); terra + areia: 2:1 (S4); terra + areia: 1:2 (S5); terra + esterco: 1:1 (S6); areia + esterco: 1:1 (S7); terra + esterco: 2:1 (S8); areia + esterco: 2:1 (S9) e terra + areia + esterco: 1:1:1 ( S10). Os diâmetros das estacas foram: 0,5 a $1,0 \mathrm{~cm}$ (D1); 1,1 a 2,0 cm (D2); e 2,1 a 3,0 cm (D3).

Os tratamentos consistiram das combinações entre os substratos e os diâmetros das estacas: T1 - S1D1; T2 - S2D1; T3 - S3D1; T4 - S4D1; T5 - S5D1; T6 - S6D1; T7 - S7D1; T8 - S8D1; T9 - S9D1; T10 - S10D1; T11 S1D2; T12 - S2D2; T13 - S3D2; T14 - S4D2; T15 - S5D2; T16 - S6D2; T17 - S7D2; T18 - S8D2; T19 - S9D2; T20 - S10D2; T21 - S1D3; T22 - S2D3; T23 - S3D3; T24 S4D3; T25 - S5D3; T26 - S6D3; T27 - S7D3; T28 - S8D3; T29 - S9D3; T30 - S10D3.

Utilizou-se: areia lavada originada de leito de rio; terra de subsolo, coletada na Fazenda Experimental da Chã de Jardim, Centro de Ciências Agrárias da UFPB; e esterco curtido de bovino. As irrigações foram realizadas diariamente com o uso de regador manual. Foram realizadas análises físicas (TAB. 1) e químicas (TAB. 2) dos substratos no Laboratório de Química e Fertilidade de Solos, do Centro de Ciências Agrárias da UFPB. 
Coletaram-se estacas de plantas matrizes em repouso vegetativo, oriundas do município de Cubati-PB, as quais foram retiradas de ramos com aproximadamente um ano e meio de idade, sendo padronizadas de acordo com os diâmetros e comprimento de $25 \mathrm{~cm}$, mantendose de quatro a seis gemas por estaca. A base das estacas foi cortada em bisel e o terço inferior imerso nos recipientes que continham os substratos. Os recipientes utilizados foram sacos de polietileno preto, com dimensões de $30 \mathrm{~cm}$ de comprimento, $9,5 \mathrm{~cm}$ de diâmetro e volume de $2.125,38 \mathrm{~cm}^{3}$.

As variáveis analisadas foram:

- Percentual de estacas enraizadas - determinado, retirando-se o saco plástico cuidadosamente, e com sucessivas lavagens obtinha-se o sistema radicular intacto, contando-se posteriormente as estacas com raízes, considerando-se enraizadas aquelas estacas com pelo menos uma raiz;

- Número de raízes - mensurado de acordo com a contagem do número médio de raízes por estaca correspondente a cada tratamento;

- Número de brotações - foram consideradas na contagem as brotações com no mínimo um centímetro de comprimento e obtida a média por estaca;

- Diâmetro das brotações - aferido a cinco centímetros da base do broto, medido em milímetro, com auxílio de paquímetro digital;
- Comprimento das brotações - medido em centímetros, a partir da base das brotações, com auxílio de régua graduada;

- Número de folhas - mensurado considerando-se o número médio de folhas emitidas por estaca;

- Massa seca média dos brotos - determinada a partir da retirada dos brotos das estacas, colocados em saco de papel devidamente identificados e levados à estufa a $65^{\circ} \mathrm{C}$ até o peso permanecer constante. Em seguida, pesado em balança de precisão para obtenção da matéria seca $(\mathrm{g})$;

- Massa seca média das raízes - obtida a partir da retirada das raízes das estacas, e utilizando-se do mesmo procedimento descrito para a massa seca dos brotos.

As avaliações foram feitas aos 70 dias após a instalação do experimento. Os dados foram analisados através de análise de variância e avaliados pelo teste de Scott Knott a 5\% de probabilidade.

\section{Resultados e discussão}

Nas Tabelas 1 e 2 estão inseridos os resultados das análises física e química dos substratos, podendo-se constatar variações na porosidade, na granulometria, na densidade e na composição química dos mesmos, as quais exerceram influência sobre as variáveis analisadas, conforme observado e discutido ao longo deste trabalho.

Tabela 1 - Características físicas dos substratos, sendo: terra (S1); areia (S2); terra + areia: 1:1 (S3); terra + areia: 2:1 (S4); terra + areia: 1:2 (S5); terra + esterco: 1:1 (S6); areia + esterco: 1:1 (S7); terra + esterco: 2:1 (S8); areia + esterco: 2:1 (S9) e terra + areia + esterco: 1:1:1 ( S10), Areia-PB, 2010

\begin{tabular}{|c|c|c|c|c|c|c|}
\hline \multirow{3}{*}{ Substratos } & \multirow{3}{*}{$\begin{array}{l}\text { Porosidade } \\
\text { total } \mathrm{m}^{3} \mathrm{~m}^{-3}\end{array}$} & \multicolumn{4}{|c|}{ Composição Granulométrica } & \multirow{3}{*}{$\begin{array}{l}\text { Densidade do } \\
\text { solo } \mathrm{g} \mathrm{cm}^{-3}\end{array}$} \\
\hline & & Areia Grossa & Areia Fina & Silte & Argila & \\
\hline & & $2-0,2 \mathrm{~mm}$ & $0,2-0,05 \mathrm{~mm}$ & $0,05-0,002 \mathrm{~mm}$ & $<0,002$ & \\
\hline S1 & 0,58 & 504 & 118 & 50 & 328 & 1,14 \\
\hline S2 & 0,45 & 845 & 133 & 22 & 00 & 1,47 \\
\hline $\mathrm{S} 3$ & 0,49 & 692 & 154 & 24 & 130 & 1,36 \\
\hline S4 & 0,53 & 579 & 168 & 48 & 205 & 1,24 \\
\hline S5 & 0,48 & 766 & 120 & 23 & 91 & 1,37 \\
\hline S6 & 0,64 & 482 & 131 & 161 & 226 & 0,90 \\
\hline S7 & 0,56 & 720 & 120 & 100 & 60 & 1,12 \\
\hline S8 & 0,62 & 455 & 138 & 116 & 291 & 0,96 \\
\hline S9 & 0,55 & 794 & 118 & 44 & 44 & 1,18 \\
\hline $\mathrm{S} 10$ & 0,57 & 648 & 147 & 117 & 117 & 1,14 \\
\hline
\end{tabular}


Tabela 2 - Propriedades químicas dos substratos, sendo: terra (S1); areia (S2); terra + areia: 1:1 (S3); terra + areia: 2:1 (S4); terra + areia: 1:2 (S5); terra + esterco: 1:1 (S6); areia + esterco: 1:1 (S7); terra + esterco: 2:1 (S8); areia + esterco: 2:1 (S9) e terra + areia + esterco: 1:1:1 ( S10), Areia - PB, 2010

\begin{tabular}{|c|c|c|c|c|c|c|c|c|c|c|c|c|c|}
\hline \multirow{2}{*}{ Substrato } & \multirow{2}{*}{$\mathrm{pH}$} & $\mathrm{P}$ & $\mathrm{K}^{+}$ & $\mathrm{Na}^{+}$ & $\mathrm{H}+\mathrm{Al}^{+}$ & $\mathrm{Al}^{+3}$ & $\mathrm{Ca}^{+2}$ & $\mathrm{Mg}^{+2}$ & SB & \multirow{2}{*}{ CTC } & $\mathrm{V}$ & $\mathrm{M}$ & \multirow{2}{*}{$\frac{\mathrm{MO}}{\mathrm{g} \mathrm{kg}^{-1}}$} \\
\hline & & \multicolumn{2}{|c|}{----mg dm-3 ---- } & \multicolumn{6}{|c|}{ - } & & \multicolumn{2}{|c|}{-------\%------- } & \\
\hline S1 & 4,83 & 3,32 & 25,42 & 0,07 & 8,42 & 0,70 & 0,85 & 0,65 & 1,64 & 10,06 & 16,30 & 29,91 & 22,00 \\
\hline S2 & 5,94 & 15,51 & 26,50 & 0,08 & 1,40 & 0,00 & 0,50 & 0,30 & 0,95 & 2,35 & 40,60 & 0,00 & 1,29 \\
\hline S3 & 4,96 & 6,30 & 27,60 & 0,08 & 6,52 & 0,30 & 0,60 & 0,65 & 1,40 & 7,92 & 17,68 & 17,65 & 8,86 \\
\hline S4 & 4,94 & 4,88 & 37,32 & 0,10 & 6,44 & 0,40 & 1,10 & 0,45 & 1,75 & 8,19 & 21,37 & 18,60 & 2,84 \\
\hline S5 & 5,04 & 9,15 & 34,08 & 0,09 & 2,48 & 0,25 & 0,80 & 0,45 & 1,43 & 3,91 & 36,57 & 14,88 & 6,84 \\
\hline S6 & 7,09 & 230,48 & 1559,41 & 3,43 & 5,53 & 0,00 & 6,30 & 2,50 & 12,79 & 18,32 & 69,81 & 0,00 & 67,53 \\
\hline S7 & 8,44 & 241,85 & 1510,77 & 3,37 & 4,54 & 0,00 & 3,60 & 3,40 & 14,23 & 18 & 75,81 & 0,00 & 53,03 \\
\hline S8 & 6,50 & 136,64 & 942,77 & 2,15 & 6,35 & 0,00 & 4,75 & 3,15 & 12,46 & 18,81 & 66,24 & 0,00 & 62,97 \\
\hline S9 & 8,27 & 159,40 & 969,87 & 2,04 & 1,73 & 0,00 & 2,95 & 2,60 & 10,07 & 11,80 & 85,34 & 0,00 & 22,73 \\
\hline S10 & 6,99 & 116,74 & 850,86 & 1,85 & 3,88 & 0,00 & 3,45 & 2,55 & 10,03 & 13,91 & 72,11 & 0,00 & 44,33 \\
\hline
\end{tabular}

Os maiores valores de porcentagem de enraizamento, números de raízes por estaca, número de brotos, diâmetro das brotações, comprimento dos brotos, número de folhas por estaca, massa seca dos brotos e massa seca das raízes foram obtidos com estacas de diâmetros D2 e D3 (Tabelas 3; 4; 5; 6; 7; 8; 9 e 10 , respectivamente).
Na Tabela 3 observa-se que os substratos não influenciaram significativamente o percentual de enraizamento, não ocorrendo o mesmo com relação aos diâmetros, onde os maiores percentuais foram verificados nas estacas com diâmetros de 1,1 a $2,0 \mathrm{~cm}(\mathrm{D} 2)$ e 2,1 a $3,0 \mathrm{~cm}$ (D3), sendo o maior valor (82\%) observado nos tratamentos S7D2 e S9D2.

Tabela 3 - Porcentagem de enraizamento em estacas de maniçoba, M. glaziovii Muell. Arg., com diferentes diâmetros aos 70 dias em diferentes substratos. Areia - PB, 2010

\begin{tabular}{lccc}
\hline \multirow{2}{*}{ Substratos } & \multicolumn{3}{c}{ Diâmetro das estacas (cm) } \\
\cline { 2 - 4 } & $0,5-1,0$ (D1) & $1,1-2,0$ (D2) & $2,1-3,0$ (D3) \\
\hline S1-Terra & 35 a B & 69 a A & 72 a A \\
S2-Areia & 29 a B & 69 a A & 54 a A \\
S3-Terra+Areia (1:1) & 19 a B & 72 a A & 79 a A \\
S4-Terra+Areia (2:1) & 22 a B & 60 a A & 69 a A \\
S5-Terra+Areia (2:1) & 35 a B & 69 a A & 50 a B \\
S6-Terra+Esterco (1:1) & 31 a B & 69 a A & 63 a A \\
S7-Areia+Esterco (1:1) & 25 a B & 82 a A & 72 a A \\
S8-Terra+Esterco (2:1) & 28 a B & 72 a A & 69 a A \\
S9-Areia+Esterco (2:1) & 28 a B & 82 a A & 69 a A \\
S10-Terra+Areia+Esterco (1:1:1) & 50 a A & 66 a A & 63 a A \\
\hline Média & 30,2 & 71 & 66 \\
\hline CV (\%) & & 31,33 & \\
\hline
\end{tabular}

Médias seguidas de mesma letra minúscula na coluna e maiúscula na linha não diferem a 5\% de probabilidade pelo teste de Scott Knott 
Biondi et al. (2008) avaliaram diferentes diâmetros de estacas $(\mathrm{T} 1=0,60$ a $0,80 \mathrm{~cm} ; \mathrm{T} 2=0,81$ a $1,00 \mathrm{~cm} \mathrm{e}$ $\mathrm{T} 3=1,01 \mathrm{a} 1,20 \mathrm{~cm}$ ) no enraizamento de ipê-de-jardim, Tecoma stans, após 100 dias e verificaram ausência de efeito, porém todos os tratamentos tiveram $100 \%$ de estacas enraizadas. Os resultados obtidos no presente estudo não estão de acordo com o autor citado, atribuindo-se a diferença de resultados às características intrínsecas das espécies.

As estacas mais lignificadas foram mais eficientes à emissão de raízes, possivelmente, devido a um maior acúmulo de reservas e à presença de cofatores de enraizamento. Os resultados obtidos não corroboram com Hartmann et al. (1990), quando afirmam que a lignificação das estacas pode funcionar como barreira física para emissão de raízes, uma vez que o maior grau de lignificação está relacionado, negativamente, com o nível de auxina, pois a peroxidase, enzima responsável pela síntese de lignina degrada a auxina. Para Herrera et al. (2004), a diferença no percentual de enraizamento entre espécies pode ser devido ao baixo nível de auxinas ou à falta de cofatores de enraizamento. Em geral, as estacas lenhosas possuem a maior quantidade de nutrientes, porém as estacas herbáceas podem ter maior concentração endógena de auxinas, por situarem-se próximo à zona de sua produção (ápices caulinares). A diferença na capacidade de enraizamento das estacas está relacionada ao estado bioquímico e fisiológico das estacas (FACHINELLO, 1995; LEONEL et al., 1991).

Para estacas com diâmetro de 1,1 a 2,0 cm (D2), os tratamentos com a composição de substratos de areia + esterco: 1:1 (S7D2) e areia + esterco: 2:1 (S9D2) proporcionaram maior percentual de enraizamento, possivelmente devido à presença dos componentes areia e esterco, cujas características físicas favoreceram a aeração na base das estacas, além de disponibilizar nutrientes, promovendo melhores condições para o enraizamento. Resultados semelhantes foram obtidos por Hoffmann et al. (1995), no enraizamento de estacas de mirtilo, Vaccinium ashei Reade, bem como por Dutra e Kersten (1996), no enraizamento de estacas de ameixeira, Prunus salicina Lindl. Segundo estes autores, a boa capacidade de drenagem e o maior espaço poroso proporcionados pela areia, assim como o equilíbrio entre os teores de água e ar teriam favorecido o elevado percentual de enraizamento em estacas destas espécies.

$\mathrm{Na}$ Tabela 4, observa-se que o maior número médio de raízes ocorreu nos tratamentos com estacas de maior diâmetro (D2 e D3). Para os diferentes substratos o número médio de raízes foi significativamente maior quando utilizou terra + areia: 1:2 (S5) e areia + esterco: 2:1 (S9) em estacas de maior diâmetro (D3).

Tabela 4 - Número médio de raízes por estaca de maniçoba, M. glaziovii Muell. Arg., com diferentes diâmetros aos 70 dias em diferentes substratos. Areia - PB, 2010

\begin{tabular}{|c|c|c|c|}
\hline \multirow{2}{*}{ Substratos } & \multicolumn{3}{|c|}{ Diâmetro das estacas (cm) } \\
\hline & $0,5-1,0(\mathrm{D} 1)$ & $1,1-2,0(\mathrm{D} 2)$ & $2,1-3,0(\mathrm{D} 3)$ \\
\hline S1-Terra & 4,38 a $\mathrm{A}$ & 7,51 a $\mathrm{A}$ & $6,28 \mathrm{~b} \mathrm{~A}$ \\
\hline S2-Areia & 3,00 a $\mathrm{A}$ & 5,34 a $\mathrm{A}$ & $7,70 \mathrm{~b} \mathrm{~A}$ \\
\hline S3-Terra+Areia $(1: 1)$ & 4,08 a $\mathrm{A}$ & 6,31 a $\mathrm{A}$ & $5,77 \mathrm{~b} \mathrm{~A}$ \\
\hline S4-Terra+Areia $(2: 1)$ & 5,79 a $\mathrm{A}$ & 8,03 a $\mathrm{A}$ & 5,29 b A \\
\hline S5-Terra+Areia $(2: 1)$ & 3,10 a B & 5,40 a B & 13,06 a $\mathrm{A}$ \\
\hline S6-Terra+Esterco $(1: 1)$ & 3,25 a $\mathrm{A}$ & 8,19 a $\mathrm{A}$ & $6,45 \mathrm{~b} \mathrm{~A}$ \\
\hline S7-Areia+Esterco $(1: 1)$ & 4,83 a $\mathrm{A}$ & 7,86 a $\mathrm{A}$ & $7,04 \mathrm{~b} \mathrm{~A}$ \\
\hline S8-Terra+Esterco $(2: 1)$ & 4,33 a $\mathrm{A}$ & 8,07 a $\mathrm{A}$ & 6,14 b A \\
\hline S9-Areia+Esterco $(2: 1)$ & 3,54 a B & 7,34 a $\mathrm{A}$ & 10,94 a A \\
\hline S10-terra+Areia+Esterco $(1: 1: 1)$ & 4,40 a $\mathrm{A}$ & 6,86 a $\mathrm{A}$ & $6,74 \mathrm{~b} \mathrm{~A}$ \\
\hline Média & 4,07 & 7,09 & 7,54 \\
\hline CV $(\%)$ & & 58,22 & \\
\hline
\end{tabular}

Médias seguidas de mesma letra minúscula na coluna e maiúscula na linha não diferem a 5\% de probabilidade pelo teste de Scott Knott 
Os resultados estão de acordo com Neves et al. (2006), que estudaram a influência de estacas herbáceas e semilenhosas de rebrotas com diâmetro de 0,8 e $1,0 \mathrm{~cm}$, respectivamente, e de estacas de muda com diâmetro de $0,9 \mathrm{~cm}$, sobre o número de raízes de estacas de corticeirada-serra, Erythrina falcata Benth., e verificaram efeito significativo dos tipos de estaca com maior incremento do número de raízes nas estacas de mudas. Possivelmente, o incremento no número de raízes por estaca observado no tratamento S5D3 $(13,06)$, ocorreu devido à presença de promotores de enraizamento presentes neste tipo de estaca, bem como ao maior acúmulo de substâncias de reservas nos mesmos.

As características físicas e químicas do substrato, pouco influenciaram a manifestação desses fatores, uma vez que se trata de uma composição com baixa acidez, baixa CTC, muito baixa saturação por bases (V\%) e teor de matéria orgânica, conforme parâmetros estabelecidos por Ribeiro et al. (1999).

Com relação ao número médio de brotações por estaca (TAB. 5) verificou-se diferença significativa tanto para o diâmetro das estacas, quanto para as composições de substratos.

As estacas com maior diâmetro (D3) emitiram maior número de brotações, possivelmente pelo fato de apresentarem maior número médio de raízes. Nos tratamentos S6D3, S7D3 e S9D3 verificou-se o maior número médio de brotações, evidenciando a influência do esterco para a variável analisada.

Os resultados obtidos estão de acordo com Tofanelli et al. (2003), que pesquisando pessegueiro da cultivar Okinawa verificaram maior percentual de brotação nas estacas de maior diâmetro, possivelmente devido à maior disponibilidade de reservas nas mesmas, favorecendo a emissão das brotações. Para Hartmann et al. (1990), as brotações são formadas a partir de reservas orgânicas.

De acordo com a Tabela 6, não houve efeito significativo dos substratos sobre os diâmetros médios das brotações emitidas, sendo os maiores valores $(6,25$ e $6,27 \mathrm{~mm}$ ) observados nas estacas de maior diâmetro (D2 e D3, respectivamente).

Esses resultados podem estar relacionados com o maior número de raízes verificadas nas estacas com maior diâmetro, proporcionando maior absorção de água e nutrientes para um maior incremento desta variável.

Observa-se na Tabela 7, que houve influência significativa dos diâmetros e substratos sobre o número médio de folhas emitidas por estaca, sendo mais elevados nos tratamentos com estacas de maior diâmetro (D2 e D3).

Tabela 5 - Número médio de brotações por estaca de maniçoba, M. glaziovii Muell. Arg., com diferentes diâmetros aos 70 dias em diferentes substratos. Areia - PB, 2010

\begin{tabular}{lccc}
\hline \multirow{2}{*}{ Substratos } & \multicolumn{3}{c}{ Diâmetro das estacas (cm) } \\
\cline { 2 - 4 } & $0,5-1,0$ (D1) & $1,1-2,0$ (D2) & $2,1-3,0$ (D3) \\
\hline S1-Terra & 1,25 a B & 1,20 a B & 1,61 b A \\
S2-Areia & 1,12 a B & 1,28 a B & 1,59 b A \\
S3-Terra+Areia (1:1) & 1,22 a B & 1,37 a B & 1,71 b A \\
S4-Terra+Areia (2:1) & 1,33 a B & 1,27 a B & 1,57 b A \\
S5-Terra+Areia (2:1) & 1,36 a A & 1,33 a A & 1,57 b A \\
S6-Terra+Esterco (1:1) & 1,38 a B & 1,31 a B & 1,97 a A \\
S7-Areia+Esterco (1:1) & 1,15 a B & 1,26 a B & 1,86 a A \\
S8-Terra+Esterco (2:1) & 1,27 a B & 1,33 a B & 1,57 b A \\
S9-Areia+Esterco (2:1) & 1,38 a B & 1,29 a B & 1,78 a A \\
S10-Terra+Areia+Esterco (1:1:1) & 1,19 a B & 1,30 a B & 1,59 b A \\
\hline Média & 1,26 & 1,29 & 1,68 \\
\hline CV (\%) & & 12,89 & \\
\hline
\end{tabular}

Médias seguidas de mesma letra minúscula na coluna e maiúscula na linha não diferem a 5\% de probabilidade pelo teste de Scott Knott 
Tabela 6 - Diâmetro médio das brotações (mm) por estaca de maniçoba, M. glaziovii Muell. Arg., com diferentes diâmetros aos 70 dias em diferentes substratos. Areia - PB, 2010

\begin{tabular}{lccc}
\hline \multirow{2}{*}{ Substratos } & \multicolumn{3}{c}{ Diâmetro das estacas (cm) } \\
\cline { 2 - 4 } & $0,5-1,0(\mathrm{D} 1)$ & $0,5-1,0(\mathrm{D} 1)$ & $0,5-1,0$ (D1) \\
\hline S1-Terra & 4,68 a B & 5,99 a A & 5,69 a A \\
S2-Areia & 4,20 a B & 5,30 a A & 5,37 a A \\
S3-Terra+Areia (1:1) & 4,13 a B & 5,40 a A & 5,40 a A \\
S4-Terra+Areia (2:1) & 4,30 a B & 5,70 a A & 5,50 a A \\
S5-Terra+Areia (2:1) & 4,02 a B & 5,34 a A & 5,15 a A \\
S6-Terra+Esterco (1:1) & 4,34 a B & 5,80 a A & 5,85 a A \\
S7-Areia+Esterco (1:1) & 4,33 a B & 5,97 a A & 5,41 a A \\
S8-Terra+Esterco (2:1) & 4,18 a C & 6,25 a A & 5,49 a B \\
S9-Areia+Esterco (2:1) & 4,20 a B & 5,92 a A & 6,27 a A \\
S10- Terra+Areia+Esterco (1:1:1) & 4,37 a B & 5,85 a A & 5,70 a A \\
\hline Média & 4,27 & 5,75 & 5,58 \\
\hline CV (\%) & \multicolumn{4}{c}{10,03} \\
\hline
\end{tabular}

Médias seguidas de mesma letra minúscula na coluna e maiúscula na linha não diferem a 5\% de probabilidade pelo teste de Scott Knott

Tabela 7 - Número médio de folhas por estaca de maniçoba, M. glaziovii Muell. Arg., com diferentes diâmetros aos 70 dias em diferentes substratos. Areia - PB, 2010

\begin{tabular}{lccc}
\hline \multirow{2}{*}{ Substratos } & \multicolumn{3}{c}{ Diâmetro das estacas (cm) } \\
\cline { 2 - 4 } & $0,5-1,0$ (D1) & $1,1-2,0$ (D1) & $2,1-3,0$ (D1) \\
\hline S1-Terra & 3,39 a B & 4,96 a A & 5,02 a A \\
S2-Areia & 2,37 a C & 3,88 b B & 4,90 a A \\
S3-Terra+Areia (1:1) & 2,67 a B & 4,05 b A & 4,81 a A \\
S4-Terra+Areia (2:1) & 2,93 a B & 4,10 b A & 4,51 a A \\
S5-Terra+Areia (2:1) & 2,57 a B & 4,22 b A & 4,39 a A \\
S6-Terra+Esterco (1:1) & 2,91 a B & 4,56 b A & 4,60 a A \\
S7-Areia+Esterco (1:1) & 3,26 a B & 4,65 b A & 5,23 a A \\
S8-Terra+Esterco (2:1) & 3,12 a B & 5,75 a A & 5,24 a A \\
S9-Areia+Esterco (2:1) & 3,08 a B & 4,81 a A & 5,68 a A \\
S10-Terra+Areia+Esterco (1:1:1) & 3,35 a B & 4,49 b A & 5,13 a A \\
\hline Média & 2,96 & 4,54 & 4,95 \\
\hline CV (\%) & & 15,06 & \\
\hline
\end{tabular}

Médias seguidas de mesma letra minúscula na coluna e maiúscula na linha não diferem a 5\% de probabilidade pelo teste de Scott Knott

O maior número de folhas observado nas estacas com diâmetro entre 2,1 e 3,0 cm (D3), provavelmente está relacionado ao maior número de raízes observado nas mesmas. De acordo com Hartmann et al. (1990), só ocorre formação de folhas se houver emissão de raízes adventícias para que haja suprimento nutricional e hídrico.
Na Tabela 7, observa-se que o aumento do diâmetro das estacas contribuiu para o aumento do número de folhas, podendo este fato está relacionado à maior quantidade de reservas acumuladas nas mesmas, devendo-se levar em consideração também as características físico-químicas do substrato. Resultado semelhante foi encontrado por Leão 
(2003), em um trabalho com enraizamento de videira, onde se pode observar que estacas mais lignificadas favoreceram o aumento do número de brotações e de folhas emitidas quando comparadas às estacas herbáceas, menos lignificadas.

O maior comprimento das brotações foi observado nas estacas com maior diâmetro (D3), verificando-se também influência do substrato sobre a variável analisada (TAB. 8).

Os maiores comprimentos das brotações em função do aumento do diâmetro das estacas estão de acordo com Biondi et al. (2008), que verificaram efeito significativo dos diâmetros de estacas de ipê-de-jardim, Tecoma stans sobre o comprimento das brotações, onde observaram maior comprimento de brotos nas estacas com diâmetro de 1,01-1,20 cm e menor nas estacas com 0,60-0,80 cm. Os resultados podem ser atribuídos não somente à maior reserva das estacas, mas também ao maior número de raízes observado nas estacas com diâmetro D3, consequentemente, as mesmas tiveram suprimento hídrico e nutricional maior que as demais estacas com diâmetro D1 e D2, o que proporcionou maior crescimento das brotações.

Com relação ao substrato, os resultados corroboram com os observados por Pereira et al. (2002), que avaliaram diferentes composições de substratos na propagação vegetativa de cafeeiro e constataram que o componente esterco exerceu influência significativa sobre o comprimento dos brotos. Segundo Pons (1983), esse material, amplamente empregado na composição de substratos constitui uma importante fonte de nitrogênio e de outros elementos essenciais ao desenvolvimento das plantas.

A massa seca dos brotos (TAB. 9) foi, significativamente, influenciada pelo diâmetro das estacas e pelos substratos, com maiores valores observados nos diâmetros D2 e D3, com destaque para os tratamentos S8D2 e S10D3.

O maior aumento de massa seca foi observado nos tratamentos com estacas de maior diâmetro, especialmente quando combinadas com o substrato S10 (Areia+Terra+Esterco: 1:1:1). Embora este tratamento S10D3 não tenha tido o melhor desempenho no que refere-se à emissão de raízes adventícias, o mesmo sobressaiu-se com relação à massa seca das brotações. Isto se explica pelo fato desta composição apresentar um melhor equilíbrio nutricional e uma capacidade intermediária de retenção de água, em comparação aos demais substratos (TAB. 1 e 2), o que conferiu um melhor crescimento da parte vegetativa.

Os diâmetros das estacas e os substratos utilizados exerceram influência significativa também sobre a produção de massa seca das raízes (TAB. 10), onde o D3 teve o melhor desempenho e a composição S8 (terra + esterco: 2:1) sobressaiu-se em D2 e em D3, em relação às demais.

Tabela 8 - Comprimento médio das brotações por estacas de maniçoba, M. glaziovii Muell. Arg., com diferentes diâmetros aos 70 dias em diferentes substratos. Areia - PB, 2010

\begin{tabular}{|c|c|c|c|}
\hline \multirow{2}{*}{ Substratos } & \multicolumn{3}{|c|}{ Diâmetro das estacas $(\mathrm{cm})$} \\
\hline & $0,5-1,0(\mathrm{D} 1)$ & $1,1-2,0(\mathrm{D} 1)$ & $2,1-3,0(\mathrm{D} 1)$ \\
\hline S1-Terra & 3,87 a B & $10,80 \mathrm{~b} \mathrm{~A}$ & 13,04 a A \\
\hline S2-Areia & 2,14 a B & $5,61 \mathrm{c} \mathrm{B}$ & $9,86 \mathrm{~b} \mathrm{~A}$ \\
\hline S3-Terra+Areia $(1: 1)$ & 3,18 a B & 8,30 с A & 10,96 b A \\
\hline S4-Terra+Areia $(2: 1)$ & 4,14 a B & 6,61 с B & 9,52 b A \\
\hline S5-Terra+Areia $(2: 1)$ & 2,19 a B & $7,01 \mathrm{c} \mathrm{A}$ & $8,41 \mathrm{~b} \mathrm{~A}$ \\
\hline S6-Terra+Esterco $(1: 1)$ & 3,51 a B & $13,02 \mathrm{~b} \mathrm{~A}$ & $9,73 \mathrm{~b} \mathrm{~A}$ \\
\hline S7-Areia+Esterco $(1: 1)$ & 4,19 a B & $10,90 \mathrm{~b} \mathrm{~A}$ & $12,04 \mathrm{~b} \mathrm{~A}$ \\
\hline S8-Terra+Esterco $(2: 1)$ & 4,88 a B & 16,07 a A & 13,67 a $A$ \\
\hline S9-Areia+Esterco $(2: 1)$ & 5,91 a C & $11,35 \mathrm{~b} \mathrm{~B}$ & 15,77 a $\mathrm{A}$ \\
\hline S10-Terra+Areia+Esterco $(1: 1: 1)$ & 4,72 a $\mathrm{C}$ & $10,18 \mathrm{~b} \mathrm{~B}$ & 15,74 a A \\
\hline Média & 3,87 & 9,98 & 11,18 \\
\hline CV (\%) & & 30,20 & \\
\hline
\end{tabular}

Médias seguidas de mesma letra minúscula na coluna e maiúscula na linha não diferem a 5\% de probabilidade pelo teste de Scott Knott 
Tabela 9 - Massa seca (g) dos brotos por estaca de maniçoba, M. glaziovii Muell. Arg., com diferentes diâmetros aos 70 dias em diferentes substratos. Areia - PB, 2010

\begin{tabular}{lccc}
\hline \multirow{2}{*}{ Substratos } & \multicolumn{3}{c}{ Diâmetro das estacas (cm) } \\
\cline { 2 - 4 } & $0,5-1,0$ (D1) & $1,1-2,0$ (D2) & $2,1-3,0$ (D3) \\
\hline S1-Terra & 2,1 a A & 3,8 a A & 4,9 b A \\
S2-Areia & 1,0 a A & 1,4 a A & 3,3 b A \\
S3-Terra+Areia (1:1) & 2,4 a A & 3,7 a A & 3,1 b A \\
S4-Terra+Areia (2:1) & 3,7 a A & 2,6 a A & 3,6 b A \\
S5-Terra+Areia (2:1) & 1,1 a A & 2,6 a A & 3,4 b A \\
S6-Terra+Esterco (1:1) & 0,9 a B & 4,7 a A & 5,1 b A \\
S7-Areia+Esterco (1:1) & 3,0 a A & 4,3 a A & 5,8 a A \\
S8-Terra+Esterco (2:1) & 1,4 a B & 6,0 a A & 6,9 a A \\
S9-Areia+Esterco (2:1) & 1,7 a B & 3,2 a B & 5,7 a A \\
S10-Terra+Areia+Esterco (1:1:1) & 2,0 a B & 3,7 a B & 8,2 a A \\
\hline Média & 1,93 & 3,6 & 5,0 \\
\hline CV (\%) & & 49,91 & \\
\hline
\end{tabular}

Médias seguidas de mesma letra minúscula na coluna e maiúscula na linha não diferem a 5\% de probabilidade pelo teste de Scott Knott

Tabela 10 - Massa seca (g) de raízes por estacas de maniçoba, M. glaziovii Muell. Arg., com diferentes diâmetros aos 70 dias em diferentes substratos. Areia - PB, 2010

\begin{tabular}{lccc}
\hline \multirow{2}{*}{ Substrato } & \multicolumn{3}{c}{ Diâmetro das estacas (cm) } \\
\cline { 2 - 4 } & $0,5-1,0$ (D1) & $0,5-1,0$ (D1) & $0,5-1,0$ (D1) \\
\hline S1-Terra & 1,84 a A & 4,20 a A & 3,18 b A \\
S2-Areia & 1,33 a B & 1,67 a B & 5,69 a A \\
S3-Terra+Areia (1:1) & 0,87 a A & 2,70 a A & 4,58 b A \\
S4-Terra+Areia (2:1) & 0,99 a B & 5,12 a A & $2,83 \mathrm{~b} \mathrm{~B}$ \\
S5-Terra+Areia (2:1) & 2,13 a A & 3,80 a A & $3,20 \mathrm{~b} \mathrm{~A}$ \\
S6-Terra+Esterco (1:1) & 2,77 a A & 3,72 a A & 6,15 a A \\
S7-Areia+Esterco (1:1) & 1,20 a A & 3,20 a A & 4,01 b A \\
S8-Terra+Esterco (2:1) & 0,86 a B & 6,47 a A & 7,87 a A \\
S9-Areia+Esterco (2:1) & 1,47 a A & 2,87 a A & 5,32 a A \\
S10-Terra+Areia+Esterco (1:1:1) & 1,90 a A & 4,07 a A & 5,53 a A \\
\hline Média & 1,53 & 3,78 & 4,83 \\
\hline CV (\%) & & 75,70 & \\
\hline
\end{tabular}

Médias seguidas de mesma letra minúscula na coluna e maiúscula na linha não diferem a 5\% de probabilidade pelo teste de Scott Knott

De maneira geral, torna-se evidente a importância e a influência das diferentes composições de substratos e dos diâmetros de estacas na propagação vegetativa e no crescimento de mudas de maniçoba. Tanto o diâmetro das estacas, quanto os substratos influenciaram praticamente em todas as variáveis analisadas, evidenciando que as composições de substratos mais favoráveis ao enraizamento, não são, necessariamente, as mesmas que proporcionam melhor desenvolvimento vegetativo das mudas. Diante disto, é necessário buscar um ponto de equilíbrio entre estes dois fatores que são efetivamente fundamentais à propagação assexuada das espécies arbóreas. 


\section{Conclusões}

1.Estacas de maniçoba com diâmetro maior que um centímetro são mais eficientes à emissão de raízes adventícias e, por conseguinte, constituem o material recomendado para a clonagem desta espécie;

2. A composição de substratos, incluindo areia + esterco proporciona de $70 \%$ a $80 \%$ de enraizamento em estacas de maniçoba.

\section{Referências}

BELTRÃO, F. A. S. et al. Morfometria de acessos de maniçoba (Manihot pseudoglaziovii Pax \& Hoffm.) e de duas espécies a fins de interesse forrageiro. Caatinga, v. 19, n. 02, p. 103-111, 2006.

BIONDI, D.; BREDOW, E. A.; LEAL, L. Influência do diâmetro de estacas no enraizamento de Tecoma stans (L.) Juss. ex Kunth. Ciências Agrárias, v. 29, n. 02, p. 277-282, 2008.

BRASIL. Ministério da Agricultura. Levantamento exploratório, reconhecimento de solos do Estado da Paraíba. Rio de Janeiro: MA/Conta/Usaid/Sudene, 1972. p.670-672. (Boletim Técnico, 15).

DUTRA, L.; KERSTEN, E. Efeito do substrato e da época de coleta dos ramos no enraizamento de estacas de ameixeira (Prunus salicina Lindl.). Ciência Rural, v. 26, n. 03, p. 361-366, 1996.

FACHINELLO, J. C. et al. Propagação de plantas frutíferas de clima temperado. 2. ed. Pelotas: UFPel, 1995. 178 p.

FERRARI, M. P.; GROSSI, F.; WENDLING, I. Propagação vegetativa de espécies florestais. Paraná: Embrapa Florestas, 2004. p. 1-19. (Documentos, 94)

FIGUEIREDO, R. W. Histórico da maniçoba no Brasil, potencialidade, multiplicação e produção. In: ENCONTRO NORDESTINO DE MANIÇOBA, 1., 1989, Recife. Anais... Recife: IPA, 1989. p. 29-57.

GRATIERI-SOSSEllA, A.; PETRY, C.; NIENOW, A. A. Propagação da corticeira do banhado (Erythrina crista-galli L.) (Fabaceae) pelo processo de estaquia. Revista Árvore, v. 32, n. 01 , p. 163-171, 2008.

HARTMANN, H. T. et al. Plant Propagation: principles and practices. 5. ed. New Jersey: Prentice Hall, 1990. cap. 9, p. 604-647.
HERRERA, T. I. et al. Efeitos de auxina e boro no enraizamento adventício de estacas caulinares de louro (Laurus nobilis L.). Biotemas, v. 17, n. 01, p. 65-77, 2004.

HOFFMANN, A. et al. Enraizamento de estacas de duas cultivares de mirtilo (Vaccinium ashei Reade) em diferentes substratos. Revista Brasileira de Agrociência, v. 01, n. 01, p. 7-11, 1995.

JABUR, M. A.; MARTINS, A. B. G. Influência de substratos na formação dos porta-enxertos: Limoeiro-cravo (Citrus limonia Osbeck) e tangerineira-cleópatra (Citrus reshni Hort. Ex Tanaka) em ambiente protegido. Revista Brasileira de Fruticultura, v. 24, n. 02, p. 514-518, 2002.

LEONEL, S. et al. Enraizamento de estacas de acerola (Malpighia glabra, Linn.). Revista Brasileira de Fruticultura, v. 13, n. 03, p. 213-217, 1991.

LEÃO, P. C. S. Utilização de diferentes tipos de estaca na produção de mudas do porta-enxerto de videira, CV. IAC 572 Jales. Ciência Rural, v. 33, n. 01, p. 165-168, 2003.

NEVES, T. S. et al. Enraizamento de corticeira-da-serra em função do tipo de estaca e variações sazonais. Pesquisa Agropecuária Brasileira, v. 41, n. 12, p. 1699-1705, 2006.

PEREIRA, A. B. et al. Enraizamento de estacas de Coffea arabica L. em diferentes substratos. Ciência Agrotecnológica, v. 26, n. 04, p. 741-748, 2002.

PONS, A. L. Fontes e usos da matéria orgânica. IPAGRO Informa, v. 26, p. 111-147, 1983.

RIBEIRO, C. A. et al. Recomendação para o uso de corretivos e fertilizantes em Minas Gerais: $5^{\text {a }}$ Aproximação. Viçosa: UFV, 1999. cap. 5, p. 25-32.

SANTOS, C. B. et al. Efeito do volume de tubetes e tipos de substratos na qualidade de mudas de Cryptomeria japonica (L. F.) D. Don. Ciência Florestal, v. 10, n. 02, p. 1-15, 2000 .

SOUZA, F. X.; LIMA, R. N. Enraizamento de estacas de diferentes matrizes de cajazeira tratadas com ácido indolbutírico. Revista Ciência Agronômica, v. 36, n. 02, p. 189-194, 2005.

TOFANELLI, M. B. D.; RODRIGUES, J. D.; ONO, E. O. Enraizamento de estacas lenhosas de pessegueiro cv. Okinawa em diferentes diâmetros de ramos, substratos e recipientes. Ciência Rural, v. 33, n. 03, p. 437- 442, 2003. 